\title{
Intersections between and understandings of literacy and disability in a B.Ed program: Discourses, tensions and curriculum
}

\author{
LUIGI IANNACCI and BENTE GRAHAM \\ Trent University
}

Over the past forty years, educators and researchers in curriculum studies have recognized that questions of what to teach, and how to teach, can never be adequately addressed without an understanding of students. This recognition and our work with teacher candidates has led us to believe that discussions of dis/ability should be prerequisites for all conversations about literacy and education. Issues of dis/ability are especially significant at this moment in time, given the numbers of students identified as "learning disabled" in provinces across Canada, the role of literacy assessments in determining students status as "learning dis/abled", and the relative lack of critical understandings of literacy and dis/ability in educational research. This paper stems from our specific experiences as teacher educators and as researchers who recognize that while questions concerning the social construction of literacy and dis/ability are rarely addressed in the province, in the country, or the field of curriculum studies, vast numbers of children and young people are experiencing some form of "special education" and modified literacy instruction. In the province of Ontario alone, more than 190,000 students (the most recent figures available), were identified by Identification Placement Review Committees (IPRC) as "exceptional pupils" during the 2004/05 school year and 99,000 other students who were not formally identified, were additionally provided with special education programs and services during that same year (Ontario Ministry of Education, 2007).

This study contributes to the growing body of research that seeks to destabilize dominant notions of literacy and disability. In particular, we explore teacher candidates' understandings and constructions of literacy and children with "special needs" ${ }^{1}$, or children identified as having a "learning disability", before and after they complete their kindergarten-grade six teacher certification (B.Ed). We examine how dominant discourses of dis/ability present themselves in these teacher candidates' initial and subsequent understandings, and how courses and a tutoring practicum can and cannot work to open up new ideas about literacy and dis/ability. Our intention is to add to the discussions of literacy education and curriculum informed by sociocultural and critical disability theory. This study highlights the connections between literacy and dis/ability as they intersect and are inextricably intertwined throughout the discourses and tensions seen in the data. Our central research questions for this study are:

- What initial understandings do teacher candidates have about literacy and young children with special needs and/or children identified as having learning disabilities prior to beginning their Bachelor of Education program?

\footnotetext{
${ }^{1}$ Children who have not been formally identified as learning disabled but have been characterized in schools and in the education literature as "at-risk", "struggling readers", "non-readers", "reluctant readers", "cognitively, linguistically, culturally deprived" or "disadvantaged" etc. (McDermott \& Varenne, 1995).
} 
- How can a tutoring placement with special needs learners and literacy focussed courses affect teacher candidates' understandings of literacy and children with special needs or children identified as having a "learning disability"?

- What is informing teacher candidates understandings of literacy and dis/ability? These questions informed by perspectives of literacy and dis/ability as socially situated and constructed have been recognized as important for researchers and activists working within New Literacy and critical disability studies (Pahl \& Rowsell, 2005; Titchosky, 2007).

\section{Theoretical Framing}

This study is informed by critical disability studies and sociocultural theories of literacy learning. These perspectives have forwarded the notion that identities such as "literate" and "disabled" are socially constructed and negotiated. Research from critical disability studies has specifically been concerned with interrogating the language used in relation to those identified as disabled and in the context of dis/ability. This interrogation examines the impact of normative discourses (e.g., able/disabled binaries) and the ways that these binaries reproduce/evoke/draw on other discourses (Pothier \& Devlin, 2006). As such, disabilities are conceptualized as something that are created from what we, as a society, do, what we consider worthy of doing, and are therefore "approached best as a cultural fabrication" (McDermott \& Varenne, 1995, p. 323) rather than as something inherent within people. As Padden \& Humphries (1988) argue "being able or unable...does not emerge as significant in itself; instead it takes on significance in the context of other sets of meaning to which the child has been exposed" (in McDermott \& Varenne, 1995, p. 325). Titchkovsky (2007) further explains:

'Disability'... is a process of meaning-making that takes place somewhere and is done by somebody. Whenever disability is perceived, spoken, or even thought about, people mean it in some way. The ways that disability comes to have meaning have something to teach us about our life-worlds. Understanding disability as a site where meaning is enacted not only requires conceptualizing disability as a social accomplishment, it also means developing an animated sense of that which enacts these meanings. (p.12)

In short, "Disabilities are less the property of persons than they are moments in a cultural focus" (McDermott \& Varenne, 1995, p. 323). Importantly, as Titchkovsky (2007) asserts, so much of the "disability discourse serves something other than the interests of disabled people... [as it] is made viable as a metaphor to express only that which is unwanted and that which is devastatingly inept" (p. 5).

In response to this positioning of disability, new approaches to students with special needs and students who have a "learning disability" within school literacy contexts are emerging. These ways of seeing and responding to these students are assetoriented (Heydon \& Iannacci, 2008) and reject "at-risk" discourses while positioning students as "at-promise" (Swadener \& Lubeck, 1995). An asset-oriented approach recognizes and builds on students" "funds of knowledge" (Moll, 1992) and therefore views learners as able, in possession of literacies and social, cognitive, artistic, emotional, cultural, linguistic, affective, epistemological etc. resources. Rather than seeing students as lacking literacy or as deficient, this perspective sees students as capable, whole and full of possibility. 
Similarly, an asset-oriented approach informed by sociocultural theory supports the notion that literacy is not just about the knowledge, acquisition, and use of a code, but is essentially a culture (Iannacci, 2007). The ways language and literacy develop are understood as a result of their use within social contexts. This perspective suggests literacy is situated, a social practice and is socially mediated. As such, how people understand, come to, and use literacy in particular social contexts and what they gain in so doing becomes a central concern for understanding what literacy is and what it does (Toohey, 2000).

In addition, this perspective recognizes the importance of seeing literacy as more than just a facility with alphabetic print. As different contexts demand a variety of specific meaning making processes people acquire multiple literacies and demonstrate their meaning making multimodally. From this perspective, texts are not restricted to the technology of alphabetic print but are varied, dynamic and take on a range of semiotic forms. This perspective recognizes that texts are privileged and marginalized differently in different contexts.

An asset-oriented approach is also informed by critical disability theory as it views disability as being "made by culture" or as a text that can be read and investigated. In this way, disability can be seen as an important "space to reread and rewrite a culture's makings" (Titchkovsky, 2007, p. 6). Examining dis/ability this way allows us to critically examine and re-evaluate dominant notions of dis/ability in ways that other theoretical perspectives do not.

Similarly, viewing literacy as cultural apprenticeship, allows us to examine the values, mores, norms and worldviews embedded in our current models of apprenticeship. It troubles what we understand about, and how we provide for children deemed to have "special needs", or to be "disabled", within the context of literacy education in ways that other popular approaches to literacy education do not. Our theoretical framework draws attention to the language assigned to children deemed "special needs" and to those who are identified as having a "disability". Using these perspectives forces us to be conscious of the ways that our use of specific terms and concepts compromise countless students' personhood and how we reify their identities in relation to limited definitions and measured "deficiencies".

As argued by Erevelles (2000) and Kliwer, Biklen, \& Kasa-Hendrickson (2006), this consideration of disability is essential for the creation of equitable schools and curricula. For although "critical theorists of education have privileged the theorization of the body along the axes of race, class, gender, and sexuality, they have consistently omitted any mention of the "disabled" body (Erevelles 2000, p. 25). This omission and exclusion "has meant that there are limited spaces in education that trouble what it means to be able or disabled or that question the curricula of disabled students" (Heydon \& Iannacci, p. 48).

Ultimately, these omissions and exclusions manifest in limited and confining instructional practices and what Cummins (2005) has described as "identity options", for all students, as they support the special education/regular education binary as well as processes of pathologiziation. For "special education students", or those deemed "reading disabled", these processes often result in a pedagogical determinism wherein students with "special needs" and "learning/reading disabilities" are assigned and resigned to 
fragmented, rote oriented, context-reduced literacy curricula (Barone, 2002, Delpit, 2003, Iannacci, 2008).

As argued by Kliwer, Biklen, \& Kasa-Hendrickson (2006) current limited understandings of dis/ability can also be traced to the devaluation of particular literacies and the denial of personhood for people perceived as disabled. In an effort to disrupt these processes and to raise questions about these practices, this study offers a critical examination of the intersections between, and the understandings of, literacy and disability in the context of an elementary B.Ed program.

\section{Literature Review}

Recent reviews of literacy and learning research suggest that dominant conceptions of these phenomena have been informed by behavioural and cognitive psychology for most of the twentieth century. As demonstrated elsewhere (Heydon \& Iannacci, 2008; Moffatt, 2006), few scholars have questioned psychological approaches to literacy education or "normal" progression in the field of curriculum studies generally, or in the field of "reading research" more specifically. While a very small group of scholars has attempted to grapple with the social construction of literacy and dis/ability, reviews of the literature (Heydon \& Iannacci, 2008; Moffatt, 2006) suggest very few researchers have actually engaged with the "symbolic complex" (a constellation of terms, concepts, practices) (Danforth, 2009), of literacy or dis/ability. Similarly, few scholars have conducted the "cultural analysis" (McDermott \& Varenne, 1995) required to fully consider how issues related to literacy and dis/ability are culturally produced or political.

As demonstrated by Heydon \& Iannacci's (2008), content analysis of four prominent, peer-reviewed, international curriculum studies' journals published over a ten year span, very few articles in the field directly or even peripherally referred to issues of dis/ability, or to curriculum for students who are disabled. Analysis suggested that each journal published a mere one to five articles concerning dis/ability throughout the decade studied.

Similarly, Moffatt's (2006) analysis of the use the term "reading disabilities" in peer reviewed journals over a five year span suggest few researchers have critically examined this term. Moffatt's (2006) analysis of 760 abstracts published between January 2000 and mid-October, 2005 suggested that $99 \%$ of the abstracts that used the term "reading disability" accepted the concept without question or did not challenge the term from a critical perspective. Similarly, $92 \%$ of the abstracts appeared to conceptualize intelligence/learning as easily assessed with standardized assessment tools.

This lack of attention to issues of disability in curriculum journals and lack of critical analysis of the term "reading disability" can be seen as reflections of dominant ideas about, literacy and disability as acultural, ahistorical, and apolitical. In addition, this lack of a sociocultural understanding of literacy and dis/ability suggests that both concepts continue to be viewed as phenomenona that reside within individuals, rather than as situated social practices (McDermott \& Varenne, 1995; Smagorinsky, 2009).

In this way, the dominant paradigm conceptualizes literacy development as "scripted habit formation" (Razfar \& Gutierrez, 2003, p. 36) and as a sequential approach to developing a student's graphophonemic cueing system. Such linear conceptualizations of literacy development have fed a "scope and sequenced" approach to literacy instruction and a focus on isolated and fragmented "bits" of language. From this 
perspective, educators and researchers have understood reading to be the domain of experts who know the "right" sequence, as well as how to detect when and whether children are in fact ready for the next step. Whole class instruction has been one of the hallmarks of reading instruction influenced by these understandings and models, and "normal" progress has been characterized as a child's ability to demonstrate mastery of the fractional components of language s/he has been exposed to during direct and often drill-based instruction. However, as argued by sociocultural theories of learning, this kind of instruction perpetuates difficulties in language learning and reinforces unequal social relations.

\section{Participants}

\section{Methodology and Design}

Participants in this study were teacher candidates enrolled in a one year Primary/Junior Bachelor of Education program in an Ontario faculty of education. Of the 240 students enrolled in the program during the year this study was conducted, 61 agreed to participate in the study by signing a consent form that was attached to a letter given to them during an initial information session held in August of the year they began their degree. Teacher candidates took the form and letter away with them in order to re-read the information and contemplate participation. Students submitted their forms to their instructors during subsequent classes. The form allowed students to indicate whether they were, or were not, willing to be involved in the study in order to avoid any public pressure to agree to participate. Consent forms were not required to be submitted until mid September in order to give teacher candidates time to make an informed decision.

Several measures were used to ensure that participants understood that they had complete freedom to decline participation. During the information session, it was made clear that the project was by no means mandatory and that not participating would have no effect on the students' grades. Further, teacher candidates were clearly told, verbally and in writing, that data generated from the study would be given to the researcher who was not their instructor. That instructor would then assign a pseudonym to the participants. Focus group interviews were also conducted by the researcher who was not the participants' course instructor. Once again, this instructor assigned these participants' pseudonyms during questionnaire data collection, organization and analysis. Focus group sessions took place after the course had ended and final grades had been submitted. Data analysis began 10 months after the teacher candidates had graduated from the program.

Data was generated for this study in three phases. In the first phase teacher candidates completed an on-line questionnaire which asked them to detail their initial background knowledge regarding literacy and students with special needs, and students identified as having a learning disability prior to the commencement of their Bachelor of Education program. In the second phase of the research, the participants completed a course taught by the researchers (Iannacci and Graham) and participated in a tutoring program described below. The participants were then asked to complete another on-line questionnaire which asked them to, once again, articulate their understandings about literacy and students with special needs and students identified as having learning disabilities. Only surveys by teacher candidates who agreed to participate in this study were then analyzed. 
Participants completed a practicum placement that required them to tutor two learners individually who had been identified as having special needs or a learning disability while they took courses grounded in sociocultural and critical disability theory. Participating schools nominated young children from grade one to grade three to participate in the tutoring program and acquired parent(s)/guardian'(s) permission in order for their children to take part. Teacher candidates attended the class once a week for two hours and also provided one-to-one literacy focused tutoring to two children separately for 45 minutes twice weekly. These aspects of their program were designed to provide the students with continuous opportunities to apply and make sense of theory and practice explored in the courses. This tutoring program was offered in addition to the 16 weeks of practicum that is part of the B.Ed program at the institution. In other words, all of the students in our classes participated in the tutoring program, even those who were not part of this current study.

In the third phase of data generation, the participants were invited to attend a focus group session where they were asked what they understood about literacy and children with special needs and/or children identified as having a learning disability and what impact the course/practicum had (if any) on their understandings of these children. During these meetings, the participants were asked to discuss an example from their tutoring placement, or a personal learning experience, that informed their understandings about literacy and children with special needs or students with a learning disability (e.g., a moment or interaction etc. that furthered, consolidated their learning or led to an assetoriented way of thinking about these students). Essentially, teacher candidates were given an opportunity to share narratives from their tutoring placement, classroom placements and/or personal learning experiences from the course that spoke to their understandings about literacy and children with special needs, and learning disabilities.

The audio-taped focus group sessions were then transcribed and both sets of questionnaires and these transcripts were read with an attention to identify recurring themes and discourses present within the data. Once these themes and discourses were identified, they were then re-examined with an eye to highlighting inconsistencies, contradictions and tensions. Triangulation therefore not only served to compare information to determine corroboration and further a process of cross-validation (OliverHoyo \& Allen, 2006), but also to make explicit complexities within the data (i.e., competing and contradictory discourses). Data was then analyzed in relation to larger social contexts (i.e., contextualizing or "nesting", Clandinin \& Connelly, 2000) by looking at various macro dynamics in relation to initial teacher candidates' understandings of literacy and children with special needs or identified as having a learning disability. This level of analysis helped to reveal some of the ways that the students were engaging with the theories presented in their courses, as well as what curricular changes needed to be made to further address dominant discourses of literacy and students with special needs or identified as learning disabled.

\section{Analysis}

This study utilizes critical discourse analysis (CDA) tools and perspectives and is therefore focused on providing a deconstructive reading and interpretation of the ways that social power, dominance, and inequity are enacted, reproduced, and resisted by text and talk (Van Dijk, 2001). CDA is commensurate with the theoretical approach of this 
study as it suggests language use is a social action, a situated performance, and is tied to social relations and identities, power, inequality, and social struggles. As argued by Slembrouck (2007), CDA can act as an inroad into understanding social phenomenon, which, in the case of this study, means providing insights into the social phenomenon known as literacy and disability. Importantly, from this perspective, discourse (much like text), is not confined to one semiotic form, and as such is

Not only a way of talking and writing, but a way of thinking and acting.

Discourse is embedded in the world view of particular social groups and is therefore tied to a set of values and norms. As people apprentice into new social practices, they become complicit with this set of values and norms, this world view (Gee, 1990).

The discourse specifically being analyzed, and thus the social phenomena being critically examined in this study focuses on teacher candidates' initial and subsequent understandings of literacy and students with special needs or those identified as having a "learning disability".

\section{Can we open up new ideas about literacy and dis/ability?: Survey data}

The first survey teacher candidates completed prior to beginning the Bachelor of Education program revealed print and decoding centric conceptualizations of literacy, a strong familiarity with deficit discourses, an understanding of "norms" and a range of conceptions concerning the causes of students" "difficulties". Many teacher candidates specifically wrote about reading as being about "sounding out words" and decoding print. Similarly, learning disabilities were often conceptualized as synonymous with difficulties and deficits in decoding print. The participants generally asserted that children who had special needs or who were identified as learning disabled had difficulty with phonics and poor phonological awareness.

The vast majority of the participants asserted a deficit-oriented view of learning disabilities and many of the participants used acronyms and terms associated with the field such as attention deficit hyperactive disorder (ADHD), attention deficit disorder (ADD) and dyslexia. Participants also often attributed learning disabilities to students' status as English as a Second Language (ESL) learners. Throughout the data these new teacher candidates who were about to begin their B.Ed program, often used words such as "delayed", "challenged", and "at-risk" to describe learners who had special needs or in reference to learning disabilities. Learning disabilities were also frequently defined as "disorders", "obstacles", "impairments" and as "inabilities". Learning disabilities were described as being about a child's "slower pace" in learning and poor performance compared to the norm. The norm was often characterized as other children of the same age and grade.

In addition, the participants suggested a range of possible causes of learning disabilities. The participants suggested that learning disabilities are the result of (in descending order): physical, neurological, biological, genetic, motivational, behavioural, emotional, familial, and social and economic factors. When familial factors were mentioned as something that resulted in a learning disability, they included (in descending order): the amount of reading supported and encouraged at home, changes in family life such as divorce or new living arrangements, emotionally abusive parents, a child having witnessed a traumatic event, abusive family relationships. Given the rise in 
child poverty over the past few decades, it bears noting that poverty and hunger were very rarely mentioned as "familial factors" that might affect learning.

When asked what they felt they would need to do for their young students who had been identified as having special needs or being learning disabled, teacher candidates focused specifically on quantitative instructional responses. In other words, they anticipated that children with special needs or children identified as learning disabled were in need of more of everything which included: more time, more one-to-one, more attention, more support and more instruction from the teacher. The participants also focused on the affective qualities of teachers working with these students. They often cited the need for teachers to be patient, to be positive, to encourage, to go above and beyond what they are expected to do for "average students" and to be committed to helping students with special needs or children identified with learning disabilities succeed.

Examining the data garnered from the second survey that teacher candidates completed when the course, the tutoring program and two thirds of their classrooms placements were completed revealed notable from the first survey. Rather than focusing on issues of decoding print, teacher candidates now described meaning making as a process that involved using a variety of resources. Such resources included various cueing systems (e.g., semantic, syntactic, critical, graphophonemic, pragmatic), that students used when constructing meaning from texts. In addition, texts were no longer defined exclusively as alphabetic print in nature, but were recognized and understood as including phenomena that included and went beyond alphabetic print. For example, one participant stated that:

"Reading is a complex process of meaning making. It is the interaction between the following systems: pragmatic, syntactic, phonographemic, semantic, orthographic and critical to make meaning of a text."

Another participant believed that:

"Reading is the ability to make meaning from a text. Such texts can be books, magazines, newspapers, but it can also be posters, television commercials. Texts need not even be strictly visual."

Teacher candidates no longer focused on quantity of instruction as it related to supporting children with special needs or a learning disability but rather the quality and nature of instruction in so far as its ability to capitalize on learners' assets. They demonstrated this by specifically discussing the need to address various modalities students' access when learning and providing them with individualized accommodations to allow them to use these modalities to demonstrate knowledge.

Changes could also be seen in the ways the participants wrote about learning disabilities. For example, in the second set of surveys, a learning disability was often conceptualized as a "learning difference".

"A learning disability is when a student is able to learn in different ways than the majority of their peers. Such students often learn in ways that are not typical, though nonetheless relevant".

However, it bears noting that deficit-oriented language taken from the special education companion of an Ontario Ministry of Education document (OCUP, 2002) that defined a variety of exceptionalities was also frequently drawn on to qualify statements. 
A learning disability is a learning disorder that manifests itself in academic and social areas of a child's life. It usually has to do with the processes that govern proper speaking and communication. Examples of such processes could be: language processing; phonological processing; visual spatial processing; processing speed; memory and attention. These disorders affect learning in individuals who otherwise demonstrate at least average abilities essential for thinking and/or reasoning. Therefore, learning disabilities should not be confused with global intellectual deficiencies.

The "learning differences" teacher candidates referred to however, were still generally defined as impairments, deficits, and/or disorders. For example, one student wrote:

A learning disability is when a student's performance does not match that of their potential. This is because the way that the information is presented in not effective for students with learning disabilities. This is usually a case of a deficit in one or more areas of oral language, reading or writing.

This contradictory conceptualization and language regarding disability was further pronounced in the survey but interestingly, asset-oriented perspectives appeared to be more prevent as teacher candidates wrote more of students" "funds of knowledge" than they did in the first survey. However, the assets they most commonly named as strengths were primarily cognitive in nature (e.g., reading strategies) rather than sociocultural. Analysis of the survey data suggests that the use of terms such as ADHD, ADD, and Dyslexia significantly declined in the second survey and that the participants did not use these terms as synonymous with having a learning disability. The participants were also much less likely to attribute a learning disability to students' status as an ESL learner in the second survey.

While these aspects of the data were encouraging, a close reading of the data revealed some significant consistencies between the first and second survey. For example, we found that although participants appeared to have shifted some of their understandings concerning literacy and learning disabilities they still named the same factors when they discussed the causes of learning disabilities. These factors also followed the same order of dominance found in the first survey. As such, physical and neurological bases for having a learning disability were cited most often. Further, although the understanding that a learning disability was about learning at a slower pace was not as prevalent as it was in the first survey, teacher candidates were more apt to focus on discussing a learning disability in comparison to norms that were linked to the Ontario Ministry of Education grade level curriculum expectations, school board mandated evaluations such as a commercially prepared and mass purchased running record system (e.g., PM Benchmarks) which defines what levels of student achievement are normal for each grade and standardized, and province wide testing as required by an "arm's-length agency of the provincial government" within Ontario known as the Education Quality Accountability Office (EQAO). Overall, (as in the first survey), there was very little engagement with the social construction of disability. A learning disability remained something that was identifiable in relation to norms.

Can we open up new ideas about literacy and dis/ability: Focus group data

In examining the focus group data, similar themes emerged. During our conversations the participants voiced broad understandings of literacy as meaning making 
and conceptualized a learning disability as a "learning difference". They also indicated that they became more attuned and responsive to students interests in and understanding of a variety of texts. However, a close analysis of the transcripts of these interviews suggests that the participants maintained fairly narrow ideas about dis/ability and its causes. In examining the data we found there was very little engagement with the social construction of dis/ability. When participants were asked about the nature of learning disabilities, participants' responses tended to focus on instructional strategies and default to discussing physical, cognitive or genetic factors.

In examining the data it also became clear that although the students were directly asked to a) address what they understood about literacy and students with special needs and/or children identified as having a learning disability, b) discuss the impact (if any) of the courses they took on their understanding of literacy and the above mentioned students and c) to provide a concrete example of an event throughout the year that informed their understandings about these students in ways that were asset-oriented, their responses were most often not about their young students, but rather about what they, the participants, did and what the teaching profession and school system does/can do to, what some of the participants referred to as, "fix" students.

The participants' responses regarding students shared significant commonalities. For example, focusing on deficits occurred most prevalently within responses that addressed a learner or learners teacher candidates encountered:

She was very low, so she would work separate from the class. But in writing she was capable but didn't enjoy writing. She knew her spelling wasn't right and so she...you know... anything she could do to not do it was just fine with her...I guess it's easy to remember the times that she wasn't doing well compared to the times when she was. I can't think of a specific time when I was like, "she's really doing great right now", kind of thing.

Some of the responses appeared to identify a child's assets. For example, in the following excerpt, a teacher candidate described working with one child who had been identified as learning disabled, and how she began to understand how much he really did know when she scribed for him.

My first placement was in a grade three classroom and there was only a few special needs, but this one student who had a learning disability and it was processing information I think. He was doing a test and I was scribing for him and I suddenly realized that he knew everything. He couldn't write it down and he needed someone to write it and I was just blown away. And I was like, "this is what a learning disability is". Like he had the information and he just couldn't get it out on paper. And that was a really big moment to see what it really is.

The rest and majority of the responses focused on what teacher candidates did instructionally, but it was not always clear how this instruction was responsive to an asset they may have previously identified. Throughout these responses we noticed a lack of connection between identified assets and teacher candidates' instructional responses. As we compared these responses, we noticed that structurally the students' responses were often organized in ways that combined the previous two types of responses (focussing on deficits, identifying assets) prior to making an unclear instructional connection to an asset that was identified. For example, one participant described her experience in this way: 
One of the girls I was tutoring, she had a lot of trouble at first. Working with her the first day, she told me she hated reading. She didn't want to do anything. You know it took a while to hook her into... she was very fidgety and would move around a lot. She liked humour a lot.....I would make some cards and we would walk around the school and I would be like, "find the card, then read them to me"....I don't know what you call it... hide the thing around the school.... [scavenger hunt]

As can be seen in this excerpt, the teacher candidate identifies humour as something the student enjoyed and therefore something that can be seen as an asset as understanding humour within texts is often a sign of well developed comprehension. However, rather than elaborating on this or demonstrating how this interest and asset was capitalized on, the candidate describes an instructional strategy - creating a "scavenger hunt" - that does not clearly align with this student's apparent interest and asset.

Analysis suggests that the participants generally found it difficult to maintain a critical stance towards the concept "learning disability". For example, at times they would attempt to question when and how disability becomes present. However, whenever these kinds of questions were raised in the focus group discussions, they were usually quickly erased as the teacher candidates defaulted towards institutional discourses and reframed their responses using the Ontario Ministry of Education definition of learning disability. The following excerpt helps to illustrate this point. In this excerpt, Teresa attempts to theorize disability with Mike and Sue, her fellow teacher candidates. Her peers seem to support her questioning at first but the discussion and questioning ends when Ministry definitions are raised and previous questioning is responded to with laughter and referred to as "off topic".

Teresa: ...maybe something is happening at home like maybe their parents are getting...you know what I mean? There's a lot of stress on them and they're coming to school and they're trying to write the number 3 and you know, it's backwards or... things are happening in the playground. There's lots of different factors. I don't think you can pinpoint and say, "Oh, you're like this because of one reason"....There are so many things that go into it.

Sue: Yeah.

Mike: So then is it possible for a student to have a learning disability one day or one week because of things going on at home and then...or even one year or two years later, and then not? Or would that not qualify as a learning disability? Is there such a thing as a temporary learning disability?

Sue: Well when I think of myself and I've got the ability to learn something if one day I'm having an emotional upheaval in my life, I'm unable to learn the way I did yesterday when I was feeling just fine and dandy, so I think a learning disability can definitely be brought on or you know triggered or be there one day and not the next day.

Mike: I don't think that's what the Ministry is talking about though.

Sue: No, I know. I knew that (laughs).

Mike: I think that's a bit off topic.

Throughout the focus groups participants often discussed ways that their placement schools were attempting to improve students' abilities to infer (a skill that comes up frequently in reference to the EQAO test children are required to complete in grade 3 and 
6 in Ontario). In speaking about this focus on making "inferences", teacher candidates raised concerns regarding the amount of time and importance placed on demonstrating the ability to infer through writing.

Tasha: I find a lot of school was really focused on inferring. And in most classes that I was in, the students could do it verbally extremely well, but when it came to writing, it was a huge challenge. I know probably it's just practice and practice. It was interesting when I was in the placement to note. I felt like everyone kept saying [to students], "You know you do it verbally really well, but we need you to practice the writing element of inferring". Like them being able to write down their inferences. You shouldn't have to be like that right? It shouldn't have to be. In line with these concerns, were teacher candidates' questions regarding which students were "allowed" to receive accommodations and modifications and which students weren't. Sarita for example, observed that one of the students in her placement required an accommodation in order for her to demonstrate knowledge she possessed. Without the accommodation, the student would not successfully be able to fulfill the evaluation she was being asked to complete. She therefore asked the associate teacher whether it was alright for her to accommodate the student.

Sarita: ...I asked the teacher, but she said unless she's on an IEP I can't.... because she's not on an IEP and she said... "If you are on an IEP. There are a couple of students that are.... But she's not one".

In this way, the institutional construction of disability delineated sanctioned instructional responses the student was allowed to have despite the student's ability to demonstrate knowledge once accommodated and the vast amounts of research and policy that stress the importance of providing instructional accommodations for students regardless of whether they have an IEP or not.

\section{Discussion}

In examining this data, we can see significant similarities and differences between the teacher candidates' conceptualizations of literacy and disability before and after their course work and tutoring placement. Perhaps one of the most striking findings is that although the courses and the tutoring program appeared to open up some new ideas about literacy, ideas about dis/ability were much more difficult to destabilize. As such, efforts and opportunities that were planned and organized in order to facilitate a challenge to dominant discourses were simultaneously successful and unsuccessful. It is interesting to note the continuity in understandings of dis/ability despite the intersections between literacy and disability as constructs.

Perhaps some of the reasons for the stability of students' understandings of disability can be explained by the widespread dominance of conceptualizations of literacy and dis/ability as found elsewhere. It is interesting to note that the conceptions of neophyte teachers prior to, and at various stages of, their initial professionalization can be seen as perfectly mirrored in the work of experienced researchers (Moffatt, 2006) who supposedly have had years of exposure to various theoretical perspectives and are, or at least should be, contributing to new understandings rather than replicating old ideas.

The continuance of such ideas can also be theorized as a result of the on-going tyranny of the norm, as a close reading of the data demonstrates how deeply teacher candidates' conceptualizations of literacy achievement and disability were dependent on 
and connected to ideas of norms. As mentioned above, these norms identified as Ministry of Education grade level expectations or "at grade level" student achievement on mandatory evaluations (e.g., EQAO, commercially prepared and purchased running records) were frequent reference points that prevented teacher candidates from fully engaging with conceptualizations of literacy and disability that were not norm-based. These conceptualizations mirror understandings Moffatt (2006) found in research reports that positioned literacy and dis/ability as measurable and identifiable through standardized assessment tools. Norm-based conceptualizations of dis/ability were specifically present in the official texts teacher candidates were exposed to and that they accessed throughout their B.Ed year. The OCUP Special Education Companion (2002) that teacher candidates used throughout their year of training, for example, is grounded in these dominant conceptualizations. Even though teacher candidates were critically prepared to interrogate the discourse embedded in the OCUP document, its official status and power as a text that defines disability often became a default option that they relied on when they experienced the uncertainly that comes with critically contemplating and destabilizing notions of dis/ability. This struggle is most apparent in the interaction cited above between Teresa, Mike and Sue.

As teacher candidates researched exceptionalities within the course, they accessed a variety of "special education" texts. Again, although they were provided with several opportunities to critically examine medical, psychometric and deficit notions of disability, the majority of these texts were informed by such perspectives. Research and theory coming from educational psychology available to teachers remains steeped in traditions and notions which inadequately theorize disability and problematically position people with disabilities as deficient in their ability to meet norms. Limited understandings of dis/ability present in these bodies of research therefore continue to live in current theory and practice as it relates to literacy, education and children with special needs or identified as learning disabled. These dynamics are far more complex than the idea that theory is value free, inherently good and something that can be transferred from one site to another in the interest of expanding knowledge and effectiveness.

As Danforth (2009) asserts:

Current efforts in ...public schools around learning disabilities utilize a series of notions whose origins and development remain greatly unexamined. Even most teachers who are prepared to teach students with identified learning disabilities know the science of learning disabilities only in an abridged and reduced form, a textbook depiction that often provides static, decontextualized lists of psycho educational characteristics. The frequent result is a two-dimensional cut-out character-the generic, multiply flawed, learning disabled child-a reified stereotype of who a child with a learning disability is as well as what that crudely crafted character cannot do (p. 15).

The contextualization Danforth (2009) advocates for is missing from the learning disabilities field and dominant notions within the field of literacy that continue to prevail. As previously stated, Heydon \& Iannacci, (2008) have pointed out that the curriculum studies field has been negligent in addressing issues of dis/ability or curriculum for students who are disabled. Moffatt's (2006) findings, offered at the beginning of this paper, demonstrate how this neglect manifests in educational research that continues to construct literacy and learning disabilities as predominantly acultural, psychometric and 
biomedical. Our current study helps illustrate how deficit-oriented understandings and discourses regarding literacy and disability persist despite extensive discussions and experiences that attempted to combat these ways of understanding and defining literacy and disability.

Other inequitable forms of relations of power were also operating in the maintenance of dominant views of disability. Specifically, the dominance and certainty of institutional discourses compromised the impact of theoretical perspectives teacher candidates encountered during the course and tutoring program. These institutional discourses, and the texts that forward them, carry a great deal of power within the teaching profession. This was most evident in the situation Sarita described. Although the information given to her by her associate teacher was inaccurate as students can be accommodated without an IEP, the ways in which official texts like an Individual Educational Plan (IEP) are perceived as sanctioning what is institutionally permissible in relation to dis/ability remained intact. The text and the authority it carries, define how dis/ability is recognized and what pedagogy it is assigned. Disability is constructed and recognized as that which is officiated by documents and that which renders responsiveness to students valid. In this way, responding to those who have not been documented as "in need" or "disabled" becomes a form of "cheating".. These dynamics position instructional responsiveness towards students with special needs, or identified as having learning disability, as "extraordinary", rather than as a means of enabling students to demonstrate knowledge in ways that are respectful of, and responsive to, the various processes, modalities and semiotic forms they engage with everyday.

An awareness of the privileging and sanctioning of particular ways of demonstrating knowledge was also evident in Tasha's description of the limited ways that children were expected to demonstrate their ability to develop inferences. Although the children were able to verbally make inferences, this way of demonstrating knowledge and therefore the knowledge itself, was rendered inferior and print-centric demonstrations were privileged. This may help to explain why teacher candidates were able to be much more asset-oriented in their discourse about literacy learning within the second survey and the focus groups, but still tended to focus on and privilege assets that were cognitive in nature (e.g., reading strategies and cueing systems).

It was unfortunate that these messages were being communicated by associate teachers as teacher candidates often view them as mentors who use exemplary practices. However, it is important to note that as practioners, associate teacher also receive strong messages about who is dis/abled, what these students are "allowed", what knowledge is valued and what modalities are privileged in demonstrating knowledge. Unfortunately, practices used by associate teachers are likely to be replicated by teacher candidates at least during their practicum, as associate teachers are responsible for evaluating whether a teacher candidate is successful in his/her placement. These power dynamics suggest some of the ways that memes, practices and problematic beliefs about dis/ability are reproduced.

Despite the fact that print-centric notions were privileged in the practices and beliefs that teacher candidates observed informing literacy and dis/ability, it was clear from the second survey and the focus group data that they developed a broader sense of text that went beyond print. Although this understanding of text did not extend to a critical reading of the text that is dis/ability, this shift is still significant. This shift could 
be seen clearly in Tasha's contribution to the focus group interview. As noted above, Tasha was able to critically recognize that there were problems inherent in limiting students to one semiotic form when attempting to assess their knowledge.

\section{Our practice}

In analyzing teacher candidates' notions of dis/ability, we (Luigi Iannacci and Bente Graham), began to take a more focused look at and critically question our own practices, course content, assignments, and curricula designed to help teacher candidates develop their understanding of literacy and dis/ability and to respond to students with special needs, or identified as having a learning disability. What we discovered was that within our own practice students were expected to complete a major assignment that both replicated dominant practices in the field of special education and notions of dis/ability.

Despite our focus on an asset-oriented approach, the assignment called for students to research an exceptionality, to look at multiple definitions of the exceptionality, to critically discuss how differing definitions contributed to the idea that disability is socially constructed, to communicate the variance of the exceptionality and identify what assets students who have been identified with this exceptionality may bring to classrooms. We then asked that students demonstrate environmental, instructional and assessment accommodations that students identified with the specific exceptionality they researched might require.

As we analyzed the data in relation to our own practice, we discovered that this assignment contributed to, rather than destabilized, dominant notions of dis/ability by ensuring that the teacher candidates' gaze was focused on a decontextualized definition of disability as opposed to what the disability means and its significance to a child. The abridged, reduced, static, two dimensional, generic, reified, stereotyped, textbook depiction of a disability that Danforth (2009) noted was exactly what we were propagating through this assignment. To some teacher candidates' credit, they still managed to remain asset-oriented and critically question depictions of disability within the material they read and used for their presentations. However, without a complete overhaul of this assignment, it is impossible to expect teacher candidates to fully develop any critical sense of dis/ability and to therefore have a full understanding of the literacies these students possess or how to instructionally respond to these students' literacies.

We have therefore re-designed this assignment so that students are creating case studies that focus on a child who has been identified as having a disability. Students will consider a variety of factors when writing the case study and contextualize the child they are writing about. Teacher candidates will be specific about what the child's exceptionality looks like and means in relation to the child. From this information they will determine what assets (literacies and otherwise) the child has and therefore what curriculum and accommodations will consider these factors and assets. What will remain at the centre of the teacher candidates' gaze is a child, rather than some obscure notion of their literacy, dis/ability and reified identity.

We recognize that this change will not fully address the replication, tensions and contradictions we discovered throughout this study with respect to teacher candidates' understandings of literacy and dis/ability. The work that needs to happen and the shifts in dynamics that need to occur for these understandings to become broadened are as 
complex as the very notions we are asking teacher candidates to destabilize. Our critical reflections regarding our own practices are offered as way of demonstrating how we as teacher educators were also implicated in replicating dominant discourses. In reflecting on this now, we share with the teacher educator community one of the practices we have revised that in part, attempts to address this replication.

\section{Conclusion}

Perspectives that contextualize and destabilize dominant notions of literacy and disability continue to have marginal status and visibility within the field of education. What is particularly disconcerting about this lack of contextualization and destabilization is the subsequent neglect of factors that contribute to who is deemed disabled and "lacking" in literacy and why disability and literacy "deficiency" presents itself. One example of this neglect can be seen in the ways in which child poverty has (or has not) been addressed. November 25, 2009 marked the 20 year anniversary of a promise made by MPs to end child poverty in Canada. Despite this promise, "activists say little progress has been achieved and [that] the situation is a national disgrace" (Raj, 2009). This is occurring at a time when "over one million Canadian children live in unsafe housing, face hunger or poor health, and have limited opportunities (Toycen, 2007, p. 2). Yet what remains intact within the field of education, is an understanding of disability and literacy (or the lack there of), as something innate that presents itself when deviations from culturally bound "normal" abilities which are psychological, neurological and measurable occur. Without engaging in contextualization, we continue ignore a variety of salient factors that need to be considered in developing fuller understandings of literacy, dis/ability and the intersections between these two constructs.

When we (Luigi and Bente), designed this research project we were interested in what the process would reveal about our own practice as we analyzed constructions of literacy and disability our students had throughout their B.Ed year. Throughout the process it became clear to us that the findings and knowledge produced were significant and transferable to other teacher education contexts that are also focused on developing future teachers' understandings of literacy, dis/ability and how to instructionally respond to students who have special needs, or are identified as having a disability.

However, our reflection does not fully recognize the work that needs to be done within the field before perspectives informed by critical disability theory and assetoriented approaches are welcomed, utilized and understood as imperative to not only reconceptualizing how we professionally develop teachers to teach, but moreover how we understand and respond to children within schools and society. We have also realized that this reconceptualization cannot occur unless the power dynamics and tensions that have been documented throughout this paper are fully considered and addressed. The current dominance of limited and limiting notions of literacy and dis/ability and their impact on children within schools require researchers working with critical perspectives to have far more influence in developing Ministry and School Board policies, procedures, protocols, and curricula as it is the ramifications of these relations of power that continue to profoundly impede the contextualization and destabilization that is desperately needed. 


\section{References}

Barone, D. (2002). Literacy teaching in two kindergarten classrooms in a school labeled at-risk. The Elementary School Journal, 102 (5), 415-441.

Danforth, S. (2009). The incomplete child: An intellectual history of learning disabilities. New York: Peter Lang.

Delpit, L. (2003). Educators as "Seed People" Growing a new future. Educational Researcher, 32 (7), 14-21.

Clandinin, J. \& Connelly, M., (2000) Narrative Inquiry: Experience and story in qualitative research. San Francisco: Jossey-Bass publications.

Cummins, J. (2001). Negotiating identities: Education for empowerment in a diverse society. CA: California Association for Bilingual Education.

Cummins, J. (2005, April). Diverse futures: Rethinking the image of the child in Canadian schools. Presented at the Joan Pederson Distinguished Lecture Series. University of Western Ontario.

EQAO. (2008). About EQAO. Queens Printer. Retrieved October, 9, 2009, from: http://www.eqao.com/AboutEQAO/AboutEQAO.aspx?status=logout\&Lang=E

Erevelles, N. (2000). Educating unruly bodies: Critical pedagogy, disability studies, and the politics of schooling. Educational Theory, 50 (1), 25-47.

Gee, J.P. (1990). Social linguistics and literacies: Ideology in discourses. Great Britain: The Falmer Press.

Heydon, R. \& Iannacci, L. (2006). Biomedical approaches to literacy: Two curriculum teachers challenge the treatment of dis/ability in contemporary early literacy education. Language \& Literacy. Special Print Edition, May 2006.

Heydon, R. \& Iannacci, L. (2008). Early childhood curricula and the de-pathologizing of childhood. University of Toronto Press.

Heydon, R. \& Iannacci, L. (2008). The pathologizing of culturally and lingusitcally diver students. In R. Heydon \& L. Iannacci, Early childhood curricula and the depathologizing of childhood. University of Toronto Press.

Iannacci, L. (2007). Learning to "Do" School: Procedural display and culturally and linguistically diverse (CLD) students in Canadian early childhood education (ECE). Journal of the Canadian Association for Curriculum Studies. 4 (2), 55-76.

Iannacci, L. (2008). The pathologizing of culturally and lingusitcally diverse students. In R. Heydon \& L. Iannacci, Early childhood curricula and the de-pathologizing of childhood. University of Toronto Press.

Kliewer, C., Biklen, D., \& Kasa-Hendrickson, C. (2006). Who may be literate? Disability and resistance to the cultural denial of competence. American Educational Research Journal, 43(2), 163-192.

Lankshear, C. \& Knobel, M. (2003). New literacies: changing knowledge and classroom learning. Buckingham, Philadelphia: Open University Press.

Language and Literacy Researchers of Canada. (May, 2008). Position statement: Language and literacy, research, educational Practice and Policy in Canada. From: http://www.csse.ca/CACS/LLRC/index.htm

McCain, M. \& Mustard, F. (1999). Reversing the real brain drain: Early years study, final report. Toronto, ON: Canadian Institute for Advanced Research.

McDermott, R., \& Varenne, H. (1995). Culture as disability. Anthropology and Education Quarterly, 26, 323-348. 
Moffatt, L. (2006). (Dis)abling readers: Discourses of literacy and learning in research on "Reading disabilities" 2000-2005. Unpublished dissertation comprehensive exam. University of British Columbia.

Moll, L. (1992). Funds of knowledge for teaching: Using a qualitative approach to connect homes and classrooms. Theory into Practice, 31(2), 132-41.

The Canadian Language and Literacy Research Network. (2009). National Strategy for Early Literacy. Originally retrieved November 23, 2009, from: http://nselwiki.cllrnet.ca/index.php/National_Strategy_for_Early_Literacy

Oliver-Hoyo, M., Allen., D.D. (2006). The Use of Triangulation Methods in Qualitative Educational Research. Journal of College Science Teaching, 35(4), 42-48.

Ontario Ministry of Education. (2002). Ontario curriculum unit planner: Special education companion. Originally Retrieved October 20, 2006, from: http://www.edu.gov.on.ca/eng/policyfunding/ocup/

Ontario Ministry of Education. (2004). The Individual Education Plan (IEP): A Resource Guide. Queen's Printer for Ontario.

Ontario Ministry of Education. (2007). Overview: An introduction to special education in Ontario. Retrieved November 15, 2007, from: http://www.edu.gov.on.ca/eng/general/elemsec/speced/ontario.html

Pahl, K., \& Rowsell, J. (2005). Literacy and Education: Understanding the new literacy studies in the classroom. Paul Chapman Publishing.

Pinar, B., Reynolds, W.M., Slattery, P. \& Taubman, P. M. (1995). Understanding curriculum. New York: Peter Lang.

Pothier, D., \& Devlin, R. (2006). Introduction: Toward a critical theory of dis-citizenship. In D. Pothier \& R. Devlin (eds.), Critical disability theory: Essays in philosophy, politics, policy, and law. Vancouver: UBC Press.

Raj, A. (2009). Child poverty in Canada is a 'national disgrace'. LFP press. Retrieved November 26, 2009, from: http://www.lfpress.com/news/canada/2009/11/24/11913961-sun.html

Razfar, A. \& Gutierrez, K. (2003). Reconceptualizing early childhood literacy: The sociocultural influence. In N. Hall, J. Larson \& J. Marsh (Eds.), Handbook of early childhood literacy (pp. 34-47).London: Sage Pub.

Smith, D. E. (1987). The everyday world as problematic: A feminist sociology. Boston: Northeastern University Press.

Slembrouck, S. (2007). What is meant by "discourse analysis"? Retrieved October 26, 2007, from: http://bank.ugent.be/da/da.htm

Swadener, B. B., \& Lubeck, S. (1995). (Eds.). Children and families “at promise”: Deconstructing the discourse of risk. Albany, NY: Albany State University of New York Press.

Taguchi, H. L. (2009). Going beyond the theory/practice divide in early childhood education: Introducing an intra-active pedagogy. UK: Routledge

Titchosky, T. (2007). Reading and writing disability differently. Toronto: University of Toronto Press.

Toohey, K. (2000). Learning English at school: Identity, social relations and classroom practice. Great Britain: Multilingual Matters Ltd.

Toycen, D. (2007). Living below the poverty line. Retrieved October, 9, 2009: From: http://www.worldvision.ca/Programs-and-Projects/CanadianPrograms/Documents/Living\%20Below\%20the\%20Line.pdf 
Triplett, C. F. (2007). The social construction of "Struggle": Influences of school literacy contexts, curriculum, and relationships. Journal of Literacy Research, 39(1), 95126.

Van Dijk, T.A. (2001). Critical Discourse Analysis. In D. Tannen, D. Schiffrin \& H. Hamilton (Eds.), Handbook of Discourse Analysis. (pp. 352-371). Oxford: Blackwell.

\section{Author Biographies}

Luigi Iannacci has taught mainstream and special education in a range of elementary grades in Ontario. He is an associate professor at in the School of Education and Professional Learning, where he teaches and coordinates the Language and Literacy course and the Supporting Literacy and Learners with Special Needs course.

Bente Graham has taught mainstream and special education in a range of elementary grades in Ontario. She is a former elementary school principal and is currently an instructor in the School of Education and Professional Learning, where she teaches and coordinates the Language and Literacy course and the Supporting Literacy and Learners with Special Needs course. 